Covered in: Web of Sciences (WOS); EBSCO; ERIH+; Google Scholar; Index Copernicus; Ideas RePeC; Econpapers; Socionet; CEEOL; Ulrich ProQuest; Cabell, Journalseek; Scipio; Philpapers; SHERPA/RoMEO repositories; KVK; WorldCat; CrossRef; CrossCheck

2018, Volume 10, Issue 3, pages: 48-59 | doi: https://doi.org/10.18662/rrem/62

\section{Is Autism Spectrum Disorders Screening Test, Valid and Reliable for Persian- Speaking Children?}

\author{
Mansoureh KARIMZADEH', \\ Ali Reza BANESHI ${ }^{2}$, \\ Mahnaz DEHGHAN \\ TEZERJANI ${ }^{3}$, \\ Robab TEYMOURI ${ }^{4}$
}

${ }^{1}$ Assistant Professor, Department of Preschool Education, Pediatric Neurorehabilitation Research Center, University of Social Welfare and Rehabilitation Sciences, Tehran, Iran, mkarimz2000@gmail.com

$2 \mathrm{a}$. PhD candidate of Psychometrics, Department of Curriculum Development \& Instruction Methods, Faculty of Psychology and Education, University of Tehran, Tehran, Iran.

b. Faculty of Psychology and Educational Sciences, Allameh Tabatabaei University, Tehran, Iran, alibaneshi4@ut.ac.ir

${ }^{3} \mathrm{PhD}$. candidate in Educational Psychology, Department of Educational Psychology, Faculty of Psychology and Education, Kharazmi University, Tehran, Iran, alibaneshi4@ut.ac.ir

${ }^{4}$ Junior Researcher, Pediatric

Neurorehabilitation Research Center, University of Social Welfare and Rehabilitation Sciences, Tehran, Iran, robab.teymouri@yahoo.com
Abstract: Background: Children with autism spectrum disorders have difficulties in developing social, language, communication and motor skills. Therefore, its early diagnosis can lead to early interventions and to improve developmental outcomes. The purpose of the study was normalization of the Autism Spectrum Disorders Screening Test, which aims to screen this disorder in lower ages (12 to 48 months).

Methods: The population of the current study was all children with neurodevelopmental disorders and normal children in Tehran. In this descriptive study, children with neurodevelopmental disorders (135 autistic and 70 intellectually disabled) and normal children (47 individuals for discriminant validity) were selected purposefully, and their parents answered the screening test (Siegel, 2004).

Results: The results of the discriminant validity indicated that the mean of three groups (normal, intellectually disabled, and autism spectrum disorder) was from lowest to the highest respectively $(\mathrm{P}=0.001)$. The cut-off point was determined score 5 and higher. The reliability of the test was 0.73 .

Conclusion: Based on the obtained findings, it seems that this test has the ability to screen Iranian children with autism spectrum disorders and intellectually disabled children.

Keywords: Normalization; screening; neurodevelopmental disorders; Autism Spectrum Disorders.

How to cite: Karimzadeh, M., Baneshi, A.R., Dehghan Tezerjani, M., \& Teymouri, R. (2018). Is Autism Spectrum Disorders Screening Test, Valid and Reliable for PersianSpeaking Children?. Revista Romaneasca pentru Educatie Multidimensionala, 10(3), 48-59.

https://doi.org/10.18662/ rrem/62 


\section{Introduction}

According to diagnostic and statistical manual for mental disordersfifth edition (DSM5), autism spectrum disorders are neurodevelopmental disorders which are with constant defect in social relationships and mutual social interactions, and repetitive and limited patterns, interests, behaviors and activities (Association, 2013). Autism and Developmental Disabilities Monitoring (ADDM) in America, which deals with the prevalence of Autism Spectrum Disorders among children under eight years old, reported that the prevalence of Autism spectrum disorders has been 14.7 per 1000 people (one per 68 people) (Wingate et al., 2014). The high rate in autism spectrum disorders prevalence entails providing effective tools in diagnosis of the disorder.

Although the symptoms of this disorder appear early during development, diagnosis of autism spectrum is delayed for years; as a result, the children lose the possibility of early interventions (Dawson \& Osterling, 1997; Filipek et al., 1999). Early intervention is essential to prevent avoidable problems of children and their families and to create recovery chance for the child (Filipek et al., 1999). One of the greatest challenges in early intervention is that clinical picture of Autism Spectrum disorder specifically in mild cases is extremely homogeneous; as a result, at the time of identification, it causes extreme difficulties even for experienced professionals (Posserud et al., 2008). Therefore, for the existence of such difficulties, it is necessary to design diagnostic tools and standardize them to help the process of diagnosis (Nelson et al., 2016).

Although autism spectrum disorders diagnostic tools such as Autism Diagnostic Observation Schedule (ADOS-G) (Lord, Rutter, DiLavore, \& Risi, 1999), ADOS-2 (Lord et al., 2012), and Autism Diagnostic Interview, Revised (ADI-R) (Le Couteur, Lord, \& Rutter, 2003) are known for their technical properties and diagnostic accuracy, their application in all applicable environments (such as clinic, school...) is impossible, as expert, educated and experienced human resources are required (Norris \& Lecavalier, 2010a, 2010b). In addition, because of the technical features and the need for experts to administer them, these tools are not useful in the early years of infancy.

However, early diagnosis of autism spectrum disorders has many advantages such as early educational and treatment planning, providing supportive, educational services for the family, reducing family's psychological stress and sorrows, and providing suitable medical care for children (Cox et al., 1999; Wiggins, Bakeman, Adamson, \& Robins, 2007). Based on the theoretical model of Dawson, taking advantage of early brain 
Is Autism Spectrum Disorders Screening Test, Valid and Reliable for... Mansoureh KARIMZADEH, et. al.

plasticity and correctable abnormalcy in brain reward circuit in early child development, even prevention of total outbreak of Autism spectrum symptoms is possible (Dawson, 2008). Therefore, the screening of autism spectrum disorders for early diagnosis is vital. The purpose of screening is early detection of children who are in danger of autism spectrum disorders to refer them for diagnostic evaluation and necessary intervention (Filipek et al., 1999). Parents' screening tools or behavioral checklists are ideal tools for early detection of Autism Spectrum Disorders, as these tools gain diagnostic data from people familiar with children and their application and screening are easy (Lord, 1995).

A lot of efforts had been made in the area of screening. By 2013, approximately 14 screening tests had been designed in which the lowest age range was considered 12 months old and the highest age range was 22 years old (Ghorbani et al., 2013). One of the Autism screening tools is Checklist for Autism in Toddlers (CHAT) which was designed by Baron-Cohen et al. (2000). The aforementioned tool is composed of two sections, the first section is filled and completed by parents and the second one by experts and it has been designed for 18 to 36-month-old children. The Modified Checklist for autism in toddlers (M-CHAT) is another tool that has been designed based on Checklist for Autism in Toddlers (CHAT) and is administered by a competent expert, and it is somewhat different from Checklist for Autism in Toddlers (CHAT) in administration method and content (Robins, Fein, Barton, \& Green, 2001).

Pervasive Developmental Disorders Screening Test-second edition (PDDST-II), which is a clinical screening tool for Autism (autistic disorder (AD) and other pervasive developmental disorders in children between 12 to 48 months old, is another screening tool for Autism Spectrum Disorders (Siegel, 2004). Pervasive Developmental Disorders Screening Test-second edition (PDDST-II) is the first screening tool for autism spectrum disorders which has some questions about the child's development in the first 48 months of life. In addition to having questions about very low age range, which is not observed in other tools, this tool is administered easily, and parents can answer the questions rapidly.

This tool is also the first screening tool which has been standardized in a large number of children who had other neurodevelopmental disorders so that by the assistance of this tool, it is possible to differentiate autism spectrum disorders from non-specific developmental delays, intellectual disability, language disorders, infant psychiatric disorders (such as attachment disorders and stress), and natural development. This questionnaire includes symptoms from three diagnostic areas of 
communication, repetitive movements and social interactions (Myles, 2007). As it was mentioned, this test is able to screen 12 to 48 month children, and as a result, it is precious, because it can assist early detection of autism spectrum disorders. Therefore, the purpose of the current research was normalization of Pervasive Developmental Disorders Screening Test-second edition (PDDST-II) among Iranian children.

\section{Methods}

\subsection{Participants}

The method of this study was descriptive. The statistical population included all children who had pervasive developmental disorder and referred to medical centers, hospitals and clinics, children of special schools in Tehran and normal children of primary schools in districts $3 \& 6$ in Tehran, in 2014 and 2015. As the group under study, autism spectrum disorders, did not have easy accessibility, the sample of the study was chosen purposefully. The subjects of the study were 252 individuals; the explanation of the frequency distribution of the participants has been reported in table 1 . The criteria for choosing children were being under 8 years of age. In relation to autistic children, diagnostic criteria were constant violation of social communication and social interactions in different situations, and restricted repetitive behavioral patterns and activities which have primarily been diagnosed by an expert or psychiatrist. For normal children, the absence of the problems has been the selection criteria.

\subsection{Instruments}

In the study, Pervasive Developmental Disorders Screening TestSecond Edition (PDDST-II) has been used .This clinical screening test which is completed by parents (as mother is the person who has the most communication with her child and knows his/her characteristics more fully, questions are preferably answered by the mother), for autism (autistic disorder), and other pervasive developmental disorders including unspecified pervasive developmental disorder and Asperger Syndrome in 12 to 48month-old children; These groups of disorders are called autism spectrum disorders. This screening test has items which are specific for development in the first 48 month of life. It should be noted that this is a retrospective test which asks questions about children's characteristics in lower ages from parents. In addition, this is the first screening test which has been standardized in a large group of children who had other neurodevelopmental disorders so that ASDs can be distinguished from non-specific 
developmental delays, intellectual disability, language disorders, infant psychiatric disorders (such as attachment disorders and stress), and natural development. This test is used when children enter a developmental services clinic (such as special education). This test has been designed for development professionals, infant educators, language pathologists, behavioral/developmental experts, psychologists and social workers to use it in environments where children are diagnosed to need developmental services for the first time. In this test, the purpose was to differentiate ASD children from those who have other developmental disorders such as language disorders or a kind of mental retardation. The purpose was to refer children with high risk of ASD for specific autism diagnosis which is necessary for intervention plans.

\subsection{Procedure}

These intervention plans are based on individual profile of autism symptoms, and learning differences. This test has 14 two- choice questions that are answered Yes, usually (point 1 ) and No, not usually ( 0 point).

Procedure of this questionnaire has been conducted in several stages as follows:

\subsubsection{Clarifying the Questionnaire:}

At first, Developmental Disorders Questionnaire was translated into Persian by a PhD Student in psychology. Next, for the first stage of clarifying, the translation was given to a professional in the area of identification of autistic children, who expressed a few problems in the translation which were modified after recognition and later she confirmed it. Then the modified translation was back translated into English by another student of psychology who had expertise in this area. Eventually, The final translation in English and original English test were sent to the main test developer for comparison who mentioned a few problems which were modified in the final stage before the first administration and an accurate translation was finally obtained.

\subsubsection{Pilot Study:}

Firstly, before administration, the experts who had expertise in the area (autism) contributed for the first administration. These colleagues concerning their expertise had close relationship with these children. For every group of autistic children (including all autism spectrum), children with mental retardation, and normal children, 10 mothers and overall, 30 mothers were selected and they answered the questionnaire. In this stage, parents were asked questions about the items' meaning and possible difficulty that 
they might have, in which few mistakes were made but were corrected afterwards. The time for the first administration was reported to be 10 minutes which was considered 15 minutes taking further steps into account.

\subsubsection{Final application:}

Final administration was done in two ways. For collecting data from two groups of mentally retarded and normal children, help was sought from Special Education Office of Tehran and Education Office of district 10 in Tehran. After contacting with Education Office and schools, the questionnaire was given to the children, and they were asked to return them to school after a week. In schools of mentally retarded children, on the basis of the previous identification that was made and investigation done by researchers and examiners ( $\mathrm{PhD}$ students of special children that had worked with autistic children and pervasive developmental disorders), it was determined that the student is mentally retarded and based on this identification, the questionnaire was given to them.

Since ASD children were important in this study and it was not easy to access them, they were identified by receiving help from related centers and clinics throughout Tehran, and suburbs with expert idea of professionals in this area and other experts who had helped in this study, with a review of clinical features based on identification guide of psychological disorders, and their parents were asked to express their children developmental features in special months of age and answer the questionnaire. It is necessary to say that data collection from these groups lasted for 7 months. Parent or person, who is familiar with the child's behavior, filled the form by checking or leaving the items of list which showed the behavior of the kid in a certain age.

\subsection{Data analysis}

In the primary stage and initial analysis of the pilot study, data distribution index, like goodness of fit (chi-square), measures of central tendency, and index of dispersion were used. In the final stage, descriptive indicators (mean and standard variation) for normalization; for checking the validity, internal consistency test, and sensitivity and specificity indicators and analysis of variance were applied.

\subsection{Ethical Considerations}

This study was confirmed by the Ethics Committee of University of Social Welfare and Rehabilitation Sciences. 


\section{Results}

The present study concluded 47 normal, 135 autistic and 70 intellectually disabled children who their parents answered to screening questionnaire. In addition, 155 of these children were boys and 97 were girls. In normal children group 23 were girls and 24 were boys, in intellectually disabled group 29 were girls and 41 were boys, and in autistic spectrum disorder group 54 were girls and 90 were boys (table 1). The mean and standard deviation of the age (the age was calculated in months) among the participants of the study were $(16.10,84.72)$ in normal group, $(28.88,43.27)$ in intellectually disabled group, and (34.66, 98.41) in autistic group respectively. The results showed that the mean of normal group, intellectually disabled group and autism spectrum is respectively from the lowest to the highest.

Table 1: frequency distribution of the participants

\begin{tabular}{cccccc}
\hline Group & Girl & Boy & Total & Mean & $\begin{array}{c}\text { Standard } \\
\text { Deviation }\end{array}$ \\
\hline Normal & 23 & 24 & 47 & 1.53 & 1.21 \\
Mentally & 29 & 41 & 70 & 3.61 & 1.9 \\
retarded & 45 & 90 & 135 & 6.5 & 2.33 \\
Autism & 97 & 155 & 252 & & \\
Total & & & &
\end{tabular}

Source: authors' own conception

The validity and reliability of the test which was done in different ways, was discussed in the first and the second stage. As it was claimed before during preparation of the questionnaire, experts of the autism confirmed the items of the test proved content validity of the test. The second method of calculating validity was discriminant validity between the groups which was conducted by comparing three groups of normal, mentally retarded and autism spectrum in the test. These differences were assessed by univariate analysis of variance. Examining the differences between variances of the three groups showed that (Levene's test) in the total score of the stage 1 in screening test $\left(\mathrm{F}_{193,1}=4.57, \mathrm{p}=0.05\right)$ there was no significant difference between the groups, which indicated the homogeneity of variance was established as the assumption of analysis of variance. In addition, univariate analysis of variance indicated that among three groups, $\left(\mathrm{MS}_{\mathrm{e}}=3.09, \mathrm{\eta}^{2}=0.53\right.$, $\left.\mathrm{F}_{252,2}=138.51, \mathrm{P}=0.001\right)$, There is a significant difference in the means obtained from the first level of test. 
Therefore, Tukey-Kramer post hoc test was used for the significance between groups. The post hoc test results in contrast between groups indicated that the mean of the normal group is lower than mentally retarded group and autism spectrum group, and the mean of the mentally retarded group is lower than from autistic group. Based on the obtained results, the test is capable of discriminating the groups from each other which means the test has discriminant validity (table 2).

Table 2: Results of Tukey post hoc test between groups

\begin{tabular}{cccl}
\hline Group & Group & Difference & \multicolumn{2}{l}{ Confidence interval } \\
\hline Normal & Autism spectrum & -5.29 & -4.41 \\
& & & 6.16 \\
Normal & Mentally retarded & -2.4 & -1.51 \\
& & & 3.3 \\
Autism spectrum & Mentally retarded & 2.89 & 3.67 \\
& & & 2.1 \\
\hline
\end{tabular}

Source: authors' own conception

To investigate the validity of the test, internal consistency (KuderRichardson 20) was used. The obtained results show that the test validity equals 0.73 .

To determine the cut- off point for screening different, two sensitivity indexes and specificity were also used. In fact, sensitivity to specificity of each question addresses the sensitivity of positive recognition of a person who has the disorder. The amount of this index is between zero to one. In addition to this, specificity means the power of a question to accurate recognition of those who lack disorder or illness. In an ideal screening test, sensitivity and specificity are considered two indexes of 1 . However, practically, the two indexes will never equal 1, and possess the score between zero to one.

The cut-off point has been determined 5 and above, and the two indexes of sensitivity and specificity with amount of 0.79 and 0.19 , were at the best balance so that they had the most ability to forecast real positive people (children who have autism disorder) and real negative (children who have been really mentally retarded, or have normal condition).

\section{Discussion}

The aim of this study was the standardization of the second stage of the Pervasive Developmental Disorders Screening Test-Second Edition (PDDST-II) among children up to the age of 8 years. The results indicated 
that the validity and reliability of Pervasive Developmental Disorders Screening Test-Second Edition (PDDST-II) is appropriate. One of the most important characteristics of diagnostic tools is to differentiate between disorders. Comparing means of the groups studied (Table 1) Showed that Pervasive Developmental Disorders Screening Test-Second Edition (PDDST-II) has discriminant validity and can distinguish children with autism spectrum disorders from normal children and children with mental retardation very well. The test also can distinguish between mental retarded and normal children.

The results of this study were consistent with the structure of the main test (Siegel, 2004). This tool is the first screening tool which has been standardized in large groups of children with neurodevelopmental disorders, so that it is possible to identify children with autism spectrum disorders from non-specific developmental delays, intellectual disability, language disorders, infant psychiatric disorders (such as attachment disorders and stress), and natural development.

As mentioned above, the aim of the second stage of Pervasive Developmental Disorder Screening Test -Second Edition (PDDST-II) was to differentiate children with autism spectrum disorders from other developmental disorders such as intellectual disability or communication disorders (Siegel, 2004) and results of the present study showed that the test could do it very well and can identify children with autism spectrum disorders from children with intellectual disability.

This differential diagnosis is so important because the ability to differentiate between the two disorders can prevent the malapropos costs that may be imposed to families. In the absence of differential diagnosis, due to the importance of early intervention for children with autism spectrum disorders and children with intellectual disability, the opportunity to receive early intervention appropriate to the problems and special needs of these children may disappear and therefore, a favorable prognosis for children cannot be possible. When a child receives a positive diagnosis in the second stage, further evaluation is needed to determine the severity of the disorder, but this early screening is also very important and can be a precursor to more accurate assessment and treatment and intervention plans.

\section{Conclusion}

Psychometric properties of screening tools for parents are usually assessed through two index of sensitivity and specificity. Sensitivity refers to the accuracy of screening children with autism spectrum disorders while 
specificity refers to the accuracy of screening the children without autism spectrum disorders. The results showed that the Pervasive Developmental Disorders Screening Test-Second Edition (PDDST-II) is desirable in terms of both sensitivity and specificity and can identify children with autism and children without autism accurately.

As whole, the results of this study showed that in terms of the psychometric properties, Pervasive Developmental Disorders Screening Test-Second Edition (PDDST-II) is suitable to identify children with autism spectrum disorder from other developmental disorders such as mental retardation and normal children. The test has good reliability and validity appropriate to identify children with autism spectrum disorders.

\section{Limitations}

One of the main limitations of this study was the lack of a similar questionnaire to assess convergent validity. In other words, there wasn't the possibility to use a questionnaire that can be used as a criterion for the identification and differential diagnosis. Also, the disproportionate number of children in different research groups as well as different numbers of children in terms of gender could be a factor which limited the interpretation of the results.

\section{Suggestions}

Based on the results, it is recommended to use the present study's test for early screening and identification of the children with autism spectrum disorders. It is also recommended to use questionnaires or diagnostic interviews on the basis of Diagnostic and Statistical Manual of Mental Disorders (DSM) with this test to examine convergent validity of the test in the next studies. It is recommended to assess other forms of Pervasive Developmental Disorders Screening Test-Second Edition (PDDST-II) in the next studies in Iran as well, to examine its psychometric properties of multi-stages for use in clinical and non-clinical environments.

\section{Acknowledgements}

Hereby, we express our gratitude to all those who helped us in conducting this research.

\section{Conflict of Interest}

The authors declared no conflict of interests. 
Is Autism Spectrum Disorders Screening Test, Valid and Reliable for... Mansoureh KARIMZADEH, et. al.

\section{References}

American Psychiatric Association. (2013). Diagnostic and statistical manual of mental disorders (DSM-5) (5th ed.). Virginia, USA: American Psychiatric Association.

Baron-Cohen, S., Wheelwright, S., Cox, A., Baird, G., Charman, T., Swettenham, J., Drew, A., \& Doehring, P. (2000). Early identification of autism by the Checklist for Autism in Toddlers (CHAT). Journal of the Royal Society of Medicine, 93(10), 521-525. doi:10.1177/014107680009301007

Cox, A., Klein, K., Charman, T., Baird, G., Baron-Cohen, S., Swettenham, J., . . . Nightengale, N. (1999). The early diagnosis of autism spectrum disorders: use of the autism diagnostic interview-revised at 20 months and 42 months of age. Journal of Child Psychology and Psychiatry, 40, 705-718.

Dawson, G. (2008). Early behavioral intervention, brain plasticity, and the prevention of autism spectrum disorder. Development and psychopathology, 20(03), 775-803. doi:10.1017/S0954579408000370.

Dawson, G., \& Osterling, J. (1997). Early intervention in autism effectvieness, common elements of current approaches. Effectiveness and common elements of current approaches. In M. J. Guralnick (Ed.), The effectiveness of early intervention: Second generation research (pp. 307-326). Baltimore, USA: Brookes.

Filipek, P. A., Accardo, P. J., Baranek, G. T., Cook Jr, E. H., Dawson, G., Gordon, B., Gravel, J. S., Johnson, C. P., Kallen, R. J., Levy, S. E., Minshew, N. J., Prizant, B. M., Rapin, I., Rogers, . J., Stone, W. L., Teplin, S., Tuchman, R. F., \& Volkmar, F. R. (1999). The screening and diagnosis of autistic spectrum disorders. Journal of Autism and Developmental Disorders, 29(6), 439484. doi:10.1023/a:1021943802493

Ghorbani, E., Seyedeyn, S., Safarian, N., Alizadeh, M., Namdar, M., Yousefi, N., \& Jalaii, S. (2013). Autism screening and diagnosis tests: A review article. Journal of Mazandaran University of Medical Sciences, 23(101), 118-133.

Retrieved from http://jmums.mazums.ac.ir/browse.php?a_id=2262\&sid=1\&slc_lang=en

Le Couteur, A., Lord, C., \& Rutter, M. (2003). The autism diagnostic interview-revised (ADI-R). Los Angeles, UA: Western Psychological Services.

Lord, C. (1995). Follow-up of two-year-olds referred for possible autism. Journal of Child Psychology and Psychiatry, 36(8), 1365-1382. doi:10.1111/j.14697610.1995.tb01669.x

Lord, C., Rutter, M., DiLavore, P., \& Risi, S. (1999). Autism diagnostic observation schedule (ADOS) manual. Los Angeles, USA: Western Psychological Services. 
Lord, C., Rutter, M., DiLavore, P., Risi, S., Gotham, K., \& Bishop, S. (2012). Autism diagnostic observation schedule (ADOS-2) (2nd ed.). Los Angeles, USA: Western Psychological Corporation.

Myles, B. S. (2007). Autism spectrum disorders: a handbook for parents and professionals. Wetport, USA: Greenwood Publishing Group.

Nelson, A. T., Lopata, C., Volker, M. A., Thomeer, M. L., Toomey, J. A., \& Dua, E. (2016). Exploratory factor analysis of SRS-2 teacher ratings for youth with ASD. Journal of Autism and Developmental Disorders, 46(9), 2905-2915. doi:10.1007/s10803-016-2822-5

Norris, M., \& Lecavalier, L. (2010a). Evaluating the use of exploratory factor analysis in developmental disability psychological research. Journal of autism and developmental disorders, 40(1), 8-20. doi:10.1007/s10803-009-0816-2

Norris, M., \& Lecavalier, L. (2010b). Screening accuracy of level 2 autism spectrum disorder rating scales: A review of selected instruments. Autism, 14(4), 263 284. doi:10.1177/1362361309348071

Posserud, M.-B., Lundervold, A. J., Steijnen, M. C., Verhoeven, S., Stormark, K. M., \& Gillberg, C. (2008). Factor analysis of the autism spectrum screening questionnaire. Autism, 12(1), 99-112. doi:10.1177/1362361307085268

Robins, D. L., Fein, D., Barton, M. L., \& Green, J. A. (2001). The modified checklist for autism in toddlers: An initial study investigating the early detection of autism and pervasive developmental disorders. Journal of Autism and Developmental Disorders, 31(2), 131-144. doi:10.1023/a:1010738829569

Siegel, B. (2004). The pervasive developmental disorders screening test II (PDDST-II). San Antonio, USA: Harcourt Assessment.

Wiggins, L. D., Bakeman, R., Adamson, L. B., \& Robins, D. L. (2007). The utility of the Social Communication Questionnaire in screening for autism in children referred for early intervention. Focus on Autism and Other Developmental Disabilities, 22(1), 33-38. doi:10.1177/10883576070220010401

Wingate, M., Kirby, R. S., Pettygrove, S., Cunniff, C., Schulz, E., Ghosh, T., Robinson, C., Lee, L. C., Landa, R., Constantino, J., Fitzgerald, R., Zahorodny, W., Daniels, J., Nicholas, J., Charles, J., McMahon, W., Bilder, D., Durkin, M., Baio, J., Christensen, D., Braun, K. V., Clayton, H., Goodman, A., Doernberg, N., Yeargin-Allsopp, M., Lott, E., Mancilla, K. C., Hudson, A., Kast, K., Jolly, K., Chang, A., Harrington, R., Fitzgerald, R., Shenouda, J., Bell, P., Kingsbury, C., Bakian, A., Henderson, A., Arneson, C., Washington, A., Frenkel, G., \& Wright, V. (2014). Prevalence of autism spectrum disorder among children aged 8 years-autism and developmental disabilities monitoring network, 11 sites, United States, 2010. MMWR Surveillance Summaries, 63(2), 1-23. Retrieved from https://www.ncbi.nlm.nih.gov/pubmed/24670961 